SHORT REPORT

\title{
Increased occupational physical activity does not improve physical fitness
}

\section{Ruzic, S Heimer, M Misigoj-Durakovic, B R Matkovic}

Aim: To determine the possible influence of high physical load in the workplace on the physical fitness of employees. Methods: The subjects (494 men) were tested by means of Baecke's questionnaire for evaluation of the Work Index, measuring occupational physical load. The EUROFIT battery of tests was used for testing the functional and motor abilities of the subjects.

Results: Subjects with a higher Work Index $(n=274)$ performed worse than the subjects with a lower Work Index $(n=220)$, indicating that high physical load in the workplace does not necessarily mean improvement in functional and motor abilities. The "heavy" workers were only found to have a stronger handgrip. This could be attributed to the fact that physical activity performed at the workplace did not have adequate intensity, volume, and duration to effect positive changes in other motor and functional capacities.

ow physical fitness is one of the major factors contributing to an increased incidence of cardiovascular disease, -diabetes mellitus, and musculoskeletal problems. There is evidence that changes in physical activity that increase physical fitness can decrease that risk. ${ }^{1}$

To a large extent, habitual physical activity levels among employees vary depending on the type of work performed. When the work is not of a sedentary nature, a large proportion of habitual physical activity is performed at the workplace. Many employees that are engaged in manual labour are reluctant to participate in recreational sports after an exhausting day at the workplace. Sometimes they assume that they have had enough exercise at the workplace. The problem that arises here concerns the quality of the physical activity performed at the workplace. Does physical activity performed at the workplace have adequate intensity, duration, and volume to effect positive changes in motor and functional abilities? Is it really the case that hard-working men and women need not take part in recreational sports in their leisure time? The aim of this study was to determine the influence of large occupational physical work volumes on

\section{Main messages}

- The habitual physical activity performed at the workplace is not related to better physical fitness in men.

- The intensity, duration, and volume of the performed physical work are not adequate to induce positive changes in the cardiorespiratory or musculoskeletal systems. motor and functional abilities in men, and to test the hypothesis that physically demanding jobs have a positive influence on the physical fitness of employees.

\section{METHODS}

The sample comprised 494 men, registered in employment, aged 20-60 years, and resident in the Republic of Croatia. The subjects were sampled by general practitioners. They were asked to send a letter of invitation to every registered employed patient between the ages of 20 and 60 . The letter comprised a short description of the procedures, and the time and date of testing. The subjects came from different educational backgrounds and were both smokers and nonsmokers. One fifth $(21 \%)$ of all contacted subjects showed up for testing, which was scheduled in the morning hours. Some subjects had to be excluded because of acute or chronic illness. Also, the subjects that participated regularly in any kind of recreational sport were not evaluated. This resulted in only $71.5 \%$ of subjects who came to testing being evaluated.

All examinees were tested by the Baecke questionnaire ${ }^{2}$ for assessment of the level of habitual physical activity. Baecke's questionnaire was chosen because of its previous positive evaluation in research. ${ }^{3}$ The questionnaire was composed of 16 items testing the physical load at work, physical load during sport activities, and physical load during leisure time. Three basic indices resulted from the application of this questionnaire: the Work Index, Sport Index, and Leisure Index. The lowest possible value of the indices was 1.0 units, signifying the lowest physical activity, while the highest possible value was 5.0 units, signifying the highest physical activity.

The subjects were divided into two groups. The first group was composed of subjects whose Work Index was lower than 3.0 units, representing a lower physical load in their jobs $(\mathrm{n}=220)$. The second group was determined by a Work Index of 3.0 units and higher, representing a higher physical load in their workplace $(n=274)$. The EUROFIT battery of tests was used in order to determine flexibility, explosive strength, repetitive strength (sit-ups), handgrip, tapping, balance, and maximal oxygen uptake. ${ }^{4}$ Flexibility was tested by means of the "sit and reach" test, explosive strength by a vertical jump, and maximal oxygen uptake was estimated by the Astrand test. ${ }^{4}$ The one-leg balance test results were gained from a number of trials needed to accomplish 30 seconds of one-leg standing; the lower the value the

\section{Policy implications}

- Employees with physically demanding jobs should be encouraged to enrol into sports/recreational programmes. 
Table 1 Means and standard deviations for each variable, and $F$ and $p$ values of MANOVA main effects analysis

\begin{tabular}{|c|c|c|c|c|}
\hline & Work Index $<3.0$ units & Work Index $\geqslant 3.0$ units & & \\
\hline & Mean (SD) & Mean (SD) & $\mathbf{F}$ & $\mathbf{p}$ \\
\hline Vertical jump (cm) & $41.7(9.2)$ & $41.3(10.4)$ & 3.470 & 0.063 \\
\hline Handgrip (N) & $558.1(98.3)$ & $585.3(84.6)$ & 2.643 & 0.023 \\
\hline Sit-ups (n) & $13.8(3.2)$ & $12.0(5.1)$ & 8.234 & 0.004 \\
\hline "Sit and reach" (cm) & $2.7(8.9)$ & $0.6(9.9)$ & 2.938 & 0.033 \\
\hline Balance (no. of trials)* & $5.83(9.07)$ & $8.6(10.9)$ & 14.877 & $<0.001$ \\
\hline Tapping (in $15 \mathrm{~s}$ ) & $30.2(5.4)$ & $27.2(5.9)$ & 38.128 & $<0.001$ \\
\hline $\mathrm{VO}_{2} \max (\mathrm{ml} / \mathrm{kg} / \mathrm{min})$ & $25.9(6.4)$ & $26.5(6.4)$ & 1.575 & 0.211 \\
\hline
\end{tabular}

better the result. The differences between the two groups were tested by ANOVA/MANOVA tests.

\section{RESULTS}

The mean value of the first group's Work Index was 2.32 (SD 0.38 ) units, while the mean value of the Work Index in the second group was $3.62(0.41)$ units; the difference was statistically significant $(\mathrm{p}<0.001)$. The groups did not differ according to age (mean (SD) 42.1 (8.4) years $v 41.7$ (8.4) years, $\mathrm{p}=0.842$ ). Only subjects whose Sport Index equalled zero were included in the study, so we were sure that none of the subjects participated in any kind of sport/recreational physical activity during their leisure time. This was also confirmed by a comparison of the Leisure Indices, which were not significantly different between the groups (mean (SD) $2.72(0.59)$ units $v 2.64$ (0.57) units, $\mathrm{p}=0.327)$, leading to the conclusion that the subjects were spending their leisure time in a similar manner regarding physical activity.

Differences in morphological characteristics that might contribute to the results of the study were also tested. The two groups did not differ according to body mass index (mean (SD) $26.8(3.4) \mathrm{kg} / \mathrm{m}^{2} v 27.2(3.7) \mathrm{kg} / \mathrm{m}^{2}, \mathrm{p}=0.084$ ).

ANOVA showed that the groups differed significantly from each other according to functional and motor abilities (Wilk's lambda 0.918, Rao's R 7.152, p < 0.001). The results of the $t$ test for independent samples showed that there was a significant difference present between the groups in all variables except the vertical jump, representing explosive strength. The group with Work Indices of 3.0 units or higher performed significantly worse than the group with Work Indices below 3.0 units. The subjects that had more workload at their workplace had lesser repetitive strength, less balance, and were less flexible than the subjects that had lower Work Indices. The group with high occupational physical load only performed better on the handgrip test. No significant differences were observed in explosive strength and aerobic capacity (table 1 ).

\section{DISCUSSION}

Some workplaces demand a significant amount of physical activity for the performance of daily assignments. This usually consists of time spent standing or walking, lifting heavy weights, or performing manual tasks. This may be the reason for the fact that some workers engaging in manual labour are reluctant to participate in any kind of sport/ recreational activity, assuming there is no need for additional physical activity after a heavy day at work.

The fact that subjects with a higher Work Index performed worse on physical fitness testing points to the conclusion that increased physical load at work does not result in better physical abilities. This could be concluded because the subjects in both groups did not participate in any kind of sport/recreational activity and there was no significant difference between the groups according to age. This leads to the assumption that the poorer performance of the subjects with a high Work Index might be attributed to persistent fatigue and chronic changes due to repetitive overload. Similar results were found in women in a previous study. ${ }^{5}$

The physical fitness surveys performed in Sweden and the $\mathrm{UK}^{67}$ did not compare physical load in the workplace with performance. Even so, the published results of these studies show many similarities in the functional and motor abilities of employed men in Sweden, the UK, and Croatia. The results of this study are contradictory to the results of Tammelin and colleagues. ${ }^{8}$ The latter found that better fitness levels were related to higher occupational physical activity. The differences might originate from the fact that their sample was much younger (birth cohort 1966) than the sample in this study. Also, Tammelin and colleagues point to the fact that some studies have suggested a reversal of the positive effect of heavy work on fitness with advancing age. However, our results are consistent with those of Nygard and colleagues, ${ }^{9}$ who concluded that jobs with mainly physical demands do not guarantee superior musculoskeletal capacity in older employees, but in their work the observed differences were not significant.

Finally, the results of this study lead us to conclude that higher physical load in the workplace does not provide adequate intensity, volume, and duration of physical tasks to induce positive changes in the aerobic capacity, strength, or flexibility of subjects. It emphasises the fact that physical activity should be planned and programmed to improve physiological capacities. The results of this study would imply the need for engagement of physically overloaded employees in organised sport/recreational activities that might improve their physical abilities.

\section{ACKNOWLEDGEMENTS}

We acknowledge the Croatian Ministry of Science and Technology.

\section{Authors' affiliations}

L Ruzic, S Heimer, M Misigoj-Durakovic, B R Matkovic, Faculty of Kinesiology, University of Zagreb, Croatia

This study is a part of a larger project, EUROFIT Croatia, sponsored by the Croatian Ministry of Health and Science and the Council of Europe

Correspondence to: Dr L Ruzic, Faculty of Kinesiology, University of Zagreb, Horvacanski zavoi 15, Zagreb 1000, Croatia; Iruzic@ffk.hr

Accepted 14 February 2003

\section{REFERENCES}

1 Erikssen G. Physical fitness and changes in mortality: the survival of the fittest. Sports Med 2001;31:571-6. 
2 Baecke JA, Burema J, Frijters JE. A short questionnaire for measurement of habitual physical activity in epidemiological studies. Am J Clin Nutr 1982;36:936-42.

3 Pols MA, Peeters PH, Bueno-De-Mesquita HB, et al. Validity and repeatability of a modified Baecke questionnaire on physical activity. Int J Epidemiol 1995;24:381-8.

4 Oja P, Tuxworth B. Eurofit for adults. Assessment of health-related fitness. Brussels: Council of Europe, 1995.

5 Heimer S, Mišigoj- Duraković M, Matković BR, et al. The influence of habitual physical activity on functional and motor abilities in middle-aged women. In: Heimer S, ed. Health related physical activity in adults. Poreč, June 2000.
6 Engström LM, Ekblom B, Forsberg A, et al. Livstil - Prestation-Hälsa. Liv 90. Rapport 1. Folksam, Högskolan för Lärautbildning. Stockholm: Karolinska Institutet, Riksidrottsförbundet, 1993.

7 The Sports Council and the Health Education Authority. National Fitness Survey Allied Dunbar. Main findings. London: The Sports Council and the Health Education Authority, 1992.

8 Tammelin T, Nayha S, Rintamaki H, et al. Occupational physical activity is related to physical fitness in young workers. Med Sci Sports Exerc 2002:34: 158-65.

9 Nygard CH, Luopajarvi T, Cedercreutz G, et al. Musculoskeletal capacity of employees aged 44 to 58 years in physical, mental and mixed types of work. Eur J Appl Physiol Occup Physiol 1987;56:555-61.

Lumbar disc degeneration is more common in Olympic athletes than in the normal population

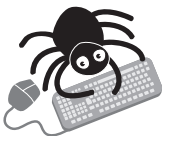

Please visit the Occupational and Environmental Medicine website [www. occenvmed. com] for a link to the full text of this article. small study of 31 elite athletes with lower back pain and/or sciatica who attended the A Polyclinic at the Sydney Olympics 2000 were found to have a higher prevalence of lumbar intervertebral disc degeneration compared with non-athletes as described in the published literature.

The athletes were competing in a range of different sports, but the largest group came from track and field $(n=12)$. Their lumbar spines were examined by MRI and looked at independently for disc signal intensity (for level of degeneration), disc height, and disc displacement.

The study found that the more caudal discs of the athletes were more likely to be abnormal. The most commonly affected disc was L5/S1; $61 \%$ of the athletes had reduced signal intensity at L5/S1 and 36\% had grade 3 degeneration. Disc height was also more reduced at the more caudal levels but only mildly so. At the L5/S1 level, 58\% had a degree of disc displacement, mostly bulging of the disc.

Other published studies have found a significant difference in the radiological appearance of the lumbar spines of athletes compared to non-athlet ++ es; disc degeneration in one study was more than twice as common (75\% compared with $31 \%$ ).

In spite of the limitations of this small study-the absence of a control group, any histories and only sagittal MR images being available - the high prevalence and degree of disc degeneration in elite athletes warrants further investigation.

A British Journal of Sports Medicine 2003;37:263-266. 